https://doi.org/10.48009/2_iis_2005_244-250

\title{
RECESSION EFFECTS ON SALARIES IN THE COMPUTING SECTOR
}

\author{
Kai S. Koong, The University of Texas Pan American, koongk@ panam.edu \\ Lai C. Liu, The University of Texas Pan American, liul@ panam.edu \\ Adnan Omar, Southern University at New Orleans, aomar@ suno.edu \\ Leetta Allen-Haynes, Southern University at New Orleans, lhaynes@suno.edu
}

\begin{abstract}
Based on government survey data that were analyzed, this study found that there are several major differences in the salary trends of computing professionals. Up through 1999, every group was reporting pay increments. Since 2000, some salaries were shown to have decreased or were increasing at a nominal rate across the board. Some job categories were more resistant than others, but overall, almost every category was affected by the economic downturn. However, when the data set was segmented by gender, the findings showed that the recession effects were very different. In some areas, male salaries continued to increase at rates that were comparable to those before the recession while female salaries for the same jobs suffered a decrease. The salary gap showed some recoveries after that. However, female salaries continued to lag behind more during the latter part of the recession period. Put another way, the evidences showed that the pay gap or inequity gap had a tendency to widen during a recessionary period as well as beyond.
\end{abstract}

Keywords: Recession, Computing Salary Trends, Compensations, Information Technology Labor Market, Gender, and Pay Inequities

\section{INTRODUCTION}

During the economic boom of the 1990s, most people were financially better off. In particular, individuals employed in the information technology sector did extremely well because computing professionals of all specializations were offered generous salaries and awarded lucrative incentives [6]. Depending on the type of skill, areas of specialization, rank, and industry type, the compensation packages offered to new hires and awarded to existing employees can be quite different. As a whole, it can be said that salaries of computing professionals were 85 percent higher than other professionals employed by the private sector $[9,12]$.

Unfortunately, a number of government reports and industry-wide research found that women in this field were found to have earned less than their male counterparts, regardless of equivalent work with commensurate skill, effort, responsibility and working conditions $[2,5,8,13,16]$. As a matter of fact, a number of studies have even attempted to explain and account for the wage discrepancy. For example, the salary gaps were believed to be caused by personal and job characteristic differences and because women are less comfortable in technical fields and because women lack salary negotiation and assertiveness skills $[1,10]$. Irrespective of the reasons or excuses offered, the reasons lack the type of scientific evidence to explain away the discrepancy [4].

Such a phenomenon in the millennium is really quite surprising and sad. A half a century has 
passed, and given the many evidences of salary inequities brought about buy race, class and gender, the government has enacted a good number of sweeping reforms to correct this practice. For example, the Equal Pay Act was signed by President John F. Kennedy in 1963. This federal legislation made it illegal for employers to pay women less than men for jobs that are "substantially equal" [14]. Of particular importance is that this legislation is based on the idea that equal work is worth equal pay, regardless of who the worker is. This law was followed by the Civil Rights Act of 1965 where other forms of discriminatory practices on the basis of race, color, sex, religion, national origin or disability were also prohibited [15]. In 1981, the Supreme Court made it clear that the Civil Rights Act prohibits wage discrimination, even when the jobs are not identical.

\section{STATEMENT OF THE PROBLEM}

In the new millennium, three major events have impacted all labor markets. From the economic downturn to the September 11 disaster and later the financial scandals that brought about the Sarbanes-Oxley Act, a lot of changes have occurred in the computing sector. Some computing jobs have become obsolete while other new ones have surfaced [6]. Many people have lost their jobs, in part due to the slowing down of the economy; others due to the practice of outsourcing to other nations, India in particular.

In the last ten years, the overall wage gap has narrowed by only four percent $[7,11]$. However, the salary gap issue in the computing sector has not improved much $[2,8,13,16]$. Actually, in the computing field, the phenomenon has even worsened [5]. For this reason, wage inequality between men and women has become an issue that contains global, economic, social, legal, and political implications because equal pay is essential to attracting the best workers and keeping America competitive in this global economy [3].

\section{STATEMENT OF THE OBJECTIVE}

This study examines the effect of the earnings of male and female IT professionals. Specifically, this research examines the magnitude as well as the direction of change that was experienced by four categories of IT professionals from 1999 through 2003. The results of this study should be of interest to all categories of information technology professionals, human resource managers, labor attorneys, federal and state policy makers, equity experts, and gender researchers. Educators, social equity scholars, placement counselors, and students selecting a program of study or entering the workforce will find this study to be particularly valuable.

\section{METHODOLOGY}

This research is an expansion of an earlier study concerning the earnings of computing professionals by Liu and Koong [5]. Similarly, data for this study were obtained from a federal source called Employment and Earnings. This annual publication is produced by the United States Department of Labor and is available free of charge. A total of 5 annual publications covering the period 1999 through 2003 were obtained for this study. According to the Bureau of Labor Statistics, the wages reported are expressed in constant dollars rather than current dollars. The Consumer Price Index (CPI) is used for converting current dollars to constant dollars. Usual 
weekly earnings included wages, overtime pay, commissions and tips before taxes. All selfemployed workers are excluded. "Usual weekly" is defined as half the weeks worked during the past four or five months. The reported data are estimated median wages.

Computer technology professionals are categorized into four subgroups. They include (a) mathematicians and computer scientists (MCS), (b) computer systems analysts and scientists (CSAS), (c) operations and systems researchers and analysts (OSRA), and (d) computer programmers $(\mathrm{CP})$. The overall population is defined as the general workforce 16 years and older and who are employed full-time.

To examine the data set, indices were first generated to examine the long-term behavior of the earnings. The base year used was 1999. Then percentages between immediate years were computed to examine the short-term behavior of the data set.

\section{FINDINGS}

An analysis of the constant dollar earnings by male and female IT professionals yielded some interesting results. From 1999 through 2003, all the job categories experienced minimal adjustments. However, there were continuous wage gaps between the two groups. In constant dollars, two of the four earning gaps appeared to have grown larger rather than smaller. Surprisingly, most of the weekly median earnings continued to rise during the recession period. However, compared to reports that were done prior to 1999 , the increases were relatively small. Moreover, many of the larger increases were followed by comparable decreases the following year. Twice, the MCS and CSAS categories showed a decrease. Both groups showed deceases in 2003. In the case of the male group, the other time was in 2000; in the case of the female group, the first time was in 2001.

Year 2001 was a great year for the males. Every male category reported an increase over the prior year. Similarly, the best year for females was 2002. Every female category reported an increase from the year earlier. In all four categories examined, men consistently received higher weekly median earnings than women. This is why the differences in weekly earnings between men and women were all positive. During these five years, the average earnings gap was largest in 2001. In three of the four categories, the gap was about $\$ 250$ per week. Since then, the average gap appeared to have reached a plateau at about $\$ 180$ a week.

Using 1999 as the base year, two of the four categories had five-year slopes that were greater than 1. The groups were MCS and CSAS and the abruptness of the slopes explained why the earnings gaps were getting larger. On the other hand, the slopes of the OSRA and CP categories are fairly close to 1 . This is why the earning gaps between the two groups are relatively stable in the case of these two categories. Other details about the behavior of the data set are presented in Table 1. 
Table 1. Index of Weekly Median Earnings of IT Professionals

\begin{tabular}{lllllll} 
CATEGORY & $\mathbf{1 9 9 9}$ & $\mathbf{2 0 0 0}$ & $\mathbf{2 0 0 1}$ & $\mathbf{2 0 0 2}$ & $\mathbf{2 0 0 3}$ & Slope \\
\hline MEN: & & & & & & \\
MCS & 100 & 99.91 & 109.75 & 110.42 & 107.01 & 1.07 \\
CSAS & 100 & 98.70 & 107.60 & 108.71 & 99.44 & 0.99 \\
OSRA & 100 & 103.57 & 112.82 & 110.71 & 120.27 & 1.20 \\
CP & 100 & 103.53 & 104.28 & 111.98 & 119.25 & 1.19 \\
AVG & 100 & 101.43 & 108.61 & 110.46 & 111.49 & 1.11 \\
WOMEN: & & & & & & \\
MCS & 100 & 102.85 & 102.51 & 107.76 & 103.42 & 1.03 \\
CSAS & 100 & 101.65 & 101.21 & 105.84 & 95.81 & 0.96 \\
OSRA & 100 & 104.61 & 104.87 & 114.98 & 127.40 & 1.27 \\
CP & 100 & 110.15 & 110.03 & 113.83 & 123.48 & 1.23 \\
AVG & 100 & 104.82 & 104.65 & 110.60 & 112.53 & 1.13 \\
GAP: & & & & & & \\
MCS & 100 & 85.56 & 145.00 & 123.33 & 124.44 & 1.24 \\
CSAS & 100 & 83.14 & 141.28 & 123.84 & 118.60 & 1.19 \\
OSRA & 100 & 98.83 & 149.12 & 91.23 & 87.72 & 0.88 \\
CP & 100 & 68.03 & 73.47 & 102.04 & 96.60 & 0.97 \\
AVG & 100 & 84.52 & 128.57 & 110.12 & 107.14 & 1.07
\end{tabular}

- In general, it can be said that earnings were relatively flat or they grew at a relatively nominal rate at best. This was especially true in the case of the MCS category. The slope was very close to 1 . Until 2002, the CSAS category was reporting earning increases. In 2003, this category reported a dramatic decrease. In fact, the slopes are less than 1 . In other words, without even accounting for inflation in 2003, CSASs were paid less than they were making in 1999. The OSRA and CP categories reported the fastest gain in real wages through the economic slow-down period. Their slopes ranged from a low of 1.19 to a high of 1.27.

- Men's weekly earnings were affected more during the beginning of the recession. In all 4 categories, they reported the lowest indices in 2000. This is the primary reason why the earnings gap was lowest that year. However, men's weekly earnings gap appeared to be extremely resilient. In 2001, their earnings appeared to have a major adjustment. The earnings gap increased in size that year. In fact, it reached a record high in three of the categories. The gap of the remaining categories peaked the following year.

Using percentages between immediate years, it showed that major attempts were made to close the earnings gap in three of the four periods. However, these adjustments were very easily offset by male earning adjustments in just one period. For example, all the categories reported a reduction in the earnings gaps between 1999 and 2000 and in three of the four categories between 2001 and 2002 and 2002 and 2003. However, the gains in the gap were all offset by adjustments to men's earning between 2000 and 2001 and 2001 and 2002. For that reason, all the gaps remained positive at the end of 2003. Other details about the behavior and magnitude of changes between the respective consecutive years are presented in Table 2. Some of the major observations about the wage gap between the two groups are also discussed below. 
Table 2. Percentage of Change between Years in Weekly Median Earnings of IT Professionals

\begin{tabular}{llllll} 
CATEGORY & $\mathbf{9 9 - 0 0}$ & $\mathbf{0 0 - 0 1}$ & $\mathbf{0 1 - 0 2}$ & $\mathbf{0 2 - 0 3}$ & $\mathbf{5}$ Years \\
\hline MEN: & & & & & \\
MCS & -0.09 & 9.86 & 0.60 & -3.09 & 1.82 \\
CSAS & -1.03 & 9.01 & 1.03 & -8.53 & 0.06 \\
OSRA & 3.57 & 8.92 & -1.86 & 8.63 & 4.82 \\
CP & 3.53 & 0.72 & 7.38 & 6.49 & 4.53 \\
AVG & 1.43 & 7.13 & 1.79 & 0.88 & 2.81 \\
WOMEN: & & & & & \\
MCS & 2.85 & -0.33 & 5.12 & -4.03 & 0.90 \\
CSAS & 1.65 & -0.43 & 4.58 & -9.48 & -0.92 \\
OSRA & 4.61 & 0.24 & 9.65 & 10.80 & 6.33 \\
CP & 10.15 & -0.12 & 3.46 & 8.47 & 5.49 \\
AVG & 4.82 & -0.16 & 5.70 & 1.44 & 2.95 \\
GAP: & & & & & \\
MCS & -14.44 & 69.48 & -14.94 & 0.90 & 10.25 \\
CSAS & -16.86 & 69.93 & -12.35 & -4.23 & 9.12 \\
OSRA & -1.17 & 50.89 & -38.82 & -3.85 & 1.76 \\
CP & -31.97 & 8.00 & 38.89 & -5.33 & 2.40 \\
AVG & -16.11 & 49.57 & -6.81 & -3.13 & 5.88
\end{tabular}

1. During the five-year period, earnings increments were negative, flat, or minimal. At best, the earnings went up by about 6 percent. At its worst, earnings went down by about a percent.

2. The CSAS category had the worst rate changes and the OSRA category the best.

3. On average, women earned about 6 percent less than men. Depending on the job category, the rate difference can be quite large. The larger rate differences were by those in the MCS and CSAS categories, a little more than 10 and 9 percent a week, respectively. Women working as OSRA and CP made about 2 percent less than their male counterparts each week.

\section{CONCLUSIONS AND IMPLICATIONS}

Using data from the United States Department of Labor, this study identified some important trends and implications about the earnings made by the four types of computing professionals. To begin, every category was affected by the recession and economic downturn that began in the latter part of 1999. However, when the outcomes were segmented by gender, the findings provided concrete evidences to show that the recession or economic downturn effects were quite different. In particular, this study found that

- In general, weekly earnings may experience nominal increases during a recession. However, any rise outside the norm will be quickly corrected during the next period. In other words, weekly earnings will have some minimum adjustments, at best. However, in most cases, they can be expected to remain relatively flat.

- Certain job categories may even experience a cut in weekly earning. The job categories are MCS and CSAS. While these two job categories may pay higher wages, they are also more volatile. In the case of the CSAS category, the slope was below 1 . In other words, the 
earnings of people working in this category are still in the recovery process. Women CSASs are worse off than their male counterparts because the rate of change was negative during this 5-year period. Persons working as OSRAs and CPs are paid less, but their earnings appear to be more resistant to the economic downturn. With the exception of female CPs, the rest appear to show an increase since 1999.

- Throughout these 5 years, men consistently earned more money than women in every category. In the cases of MCS and CSAS, this gap grew since 1999. In the cases of OSRA and $\mathrm{CP}$, the corrections were minimal.

- It appeared that there were some minor attempts to correct the earning inequities throughout the 5 years. However, the corrections were offset by sudden and very large differences in pay hikes by men in 2000-01 and 2001-02.

In general, women MCSs and CSASs are making about 10 percent less a week than their male counterparts and women OSRAs and CPs are making about 2 percent less a week. Putting this into perspective and using earnings as the sole difference, this means that MCS and CSAS women must work at least 6 extra weeks to earn the same money as their male counterparts. In the case of OSRA and CP women, they will have at least 7 extra days to earn the same amount of money as their male counterparts. When other factors such as retirement contributions and benefits are added, it will translate to about two months for the former group and two weeks for the latter group. Computed over the long run, it is no wonder that women may have to work an extra year or two to obtain an equitable retirement outcome.

In the new millennium, this type of an inequity is bad for employee morale and the productivity of the labor force. Irrespective of reasons, causes, and excuses, pay inequity is a sensitive and demoralizing phenomenon. For this reason, the findings here should be taken seriously. At the micro-level, discrepancies can lead to expensive lawsuits between employees and their employers. At the macro-level, unequal compensation based on any kind of race, class, and gender issues is also unhealthy for the economy.

Solving this problem can be a simple one, but it can also be a difficult task because performance assessment standards must now include adjustment factors that may include sensitive demographic attributes. To begin, it may be necessary to educate existing and future managers about the importance of pay equity. Second, it is also necessary to point out that equity must be assessed continuously using multiple measures. The indices and percentages used here for evaluating long term and short-term progress is a good starting point. Like it or not, the goal is to have the real dollar difference between the two groups approximate zero.

\section{REFERENCES}

1. England P. (1992). Comparable Worth: Theories and Evidence. New York: Aldine de Gruyter.

2. Fabris, P. (March 1998). For What You're Worth. CIO Magazine, 11(10), 60-66.

3. Garza, I. (June 22, 2000). Worth More Than We Earn: Fair Pay for Working Women, available at http://www.dol.gov/dol/wb/public/programs/fpcworth.htm. 
4. Levine, L. (June 12, 2000). Congressional Research Service Report for Congress 95-661: The Male-Female Wage Gap: A Fact Sheet, available at http://www.cnie.org/nle/econ65.html.

5. Liu, L. C. \& Koong, K. S. (2003). Some Observations on Gender and Wage Differences in the Information Technology Sector, Issues in Information Systems, 4(2), 582-588.

6. Koong, K. S., Liu, L. C. \& Fowler, R. (2003). Salaries of Information Technology Managers: A Trend Analysis, Journal of International Technology and Information Management, 12(1), 93-105.

7. Mason, B. (March 2001). What Women Want (Equal Pay Task Force), People Management, 7(5), 53.

8. Matevaschuk, J. (April 1999). Gender Gap is Smaller in Technology, InformationWeek, 731, 54.

9. Menezes, J. (August 1999). Pay Rates Reveal IT's Gender Gap, Computing Canada, 25(31), 11-12.

10. Pfeffer, J. \& Blake, D. (1987). The Effect of the Proportion of Women on Salaries: The Case of College Administrators, Administrative Science Quarterly, 32, 1-24.

11. Rowel, A. (January 15, 2001). The Fence: Should Women Earn the Same as Men? available at http://www.thefence.com/debate.asp3fforumid\%3D234.

12. Shapiro, R. J., Price, L., \& Mayer, J. (2000). Digital Economy 2000: Office of Policy Development, Economic and Statistics Administration. Washington: U.S. Department of Commerce, xiii.

13. Trombly, M. (February, 2001). Wall Street IT Women Trail Men in Pay, Computerworld, 35(7), 14.

14. United States Code. (1963). Equal Pay Act, Section 206(d), 29, Pub. L. 88-38.

15. United States Code. (1965). Civil Rights Act, Pub L. 88-3.

16. Wilde, C. (June 2000). Women in IT Strive for Equal Job Compensation, InformationWeek, 790, 226-229. 